\title{
Leis também produzem o espaço: contando a história de Jardim Laranjeiras (RJ)
}

Tatiana Cotta Gonçalves Pereira ${ }^{1}$

\section{RESUMO}

0 presente artigo busca contar a história da ocupação de uma área a partir do levantamento da incidência de algumas leis, com o objetivo de demonstrar como a legislação urbanística também é responsável pela produção dos espaços sociais. Tomando como referência as categorias "espaço concebido" e "espaço percebido" do filósofo francês Henri Lefebvre, busca-se olhar para o local que uma comunidade vive há mais de meio século e compreender como e em que medida a norma jurídica ajudou a configurá-lo. Assim, esse espaço será identificado juridicamente como um loteamento irregular (micro espaço) em uma periferia da Região Metropolitana do Rio de Janeiro (macro espaço). A irregularidade fundiária e a demanda por regularização serão demonstradas nos aspectos legislativos e processuais. A periferização estabelece uma forma específica de inserção na dinâmica metropolitana, que contribui para um determinado papel para esse espaço, papel até aqui reforçado pelas normas jurídicas e que, apenas muito recentemente, intentam modifica-lo. Os aspectos territoriais micro e macro são, desta forma, observados a partir das normas jurídicas que ali atuam e, portanto, definem a configuração daquele espaço, tanto em seu sentido de espaço concebido quanto de espaço percebido.

PALAVRAS-CHAVE: Leis urbanísticas; Produção do espaço; Processos socioespaciais

\section{ABSTRACT}

The present article tries to tell the history of the occupation of an area from the survey of the incidence of some laws, with the purpose of demonstrating how urban legislation is also responsible to produce social spaces. Taking as reference the categories "conceived space" and "perceived space" of the French philosopher Henri Lefebvre, we seek to look at the place that a community has lived for more than half a century and to understand how and to what extent the juridical norm helped to configure it. Thus, this space will be legally identified as an irregular allotment (micro space) in a periphery of the Metropolitan Region of Rio de Janeiro (macro space). The land irregularity and the demand for regularization will be demonstrated in the legislative and procedural aspects. The peripheralization establishes a specific form of insertion in the metropolitan dynamics, which contributes to a certain role for this space, a role hitherto reinforced by legal norms and which, very recently, have attempted to modify it. The micro and macro territorial aspects are thus observed from the legal norms that act there and, therefore, define the configuration of that space, both in its sense of conceived space and perceived space.

KEYWORDS: Urbanistic laws; Production of space; Socio-spatial processes

\section{Introdução}

O espaço, o território, o lugar e a paisagem são categorias da geografia e da arquitetura, causando certa estranheza que o jurista possa, de alguma forma, contribuir na análise empírica dessas categorias. Contudo, não é possível esquecer que toda forma de ocupação do espaço está mediada por normas jurídicas que interferem, portanto, naquela configuração.

1 Doutora em Ciências Sociais e Jurídicas (UFF) Professora de Direito Ambiental e Urbanístico no Programa de Pós Graduação em Desenvolvimento Territorial e Políticas Públicas e no curso de Direito, ambos da UFRRJ, Seropédica, Brasil. 
Assim, quando se definem áreas non aedificandi, tamanhos mínimos de lotes, usos permitidos e proibidos para o solo urbano, dentre outras regulamentações, a legislação urbanística necessariamente está ajudando a definir a forma socioespacial.

Além disso, a tradução jurídica do espaço - ou do território - é o direito de propriedade imobiliária, ou seja, para o ordenamento jurídico, o acesso à terra é realizado através do acesso à propriedade do solo. Desta forma, muitas vezes a realização do direito fundamental à moradia digna não se realiza plenamente para uma parcela significativa da população porque esta não consegue acessar facilmente tal direito.

Nesse sentido, o presente artigo visa demonstrar as leis que ajudaram a configurar o território ocupado pelo loteamento irregular Jardim Laranjeiras, formado na década de 1950, que se constitui como parte do bairro de Cabuçu, no município de Nova Iguaçu.

A precariedade da área - reconhecida no Plano Diretor de Nova Iguaçu - não está apenas relacionada ao seu aspecto periférico, como também pelo fato da lei de parcelamento do solo então vigente, bem como as regulamentações municipais, facilitarem uma ocupação sem infraestrutura, gerando um espaço sem serviços básicos, típico bairro habitado pela população pobre, configurado como periferia.

Essa condição acaba por demandar, anos mais tarde, a regularização fundiária em todas as suas dimensões - urbanística, jurídica, social e ambiental. Assim, a comunidade se organiza através da Associação de Moradores do Bairro Jardim Laranjeiras, e acaba obtendo diversas conquistas, como a eletrificação da área e transporte público, crescendo tanto que passa a ser considerado um "bairro informal" na região. Além disso, é também beneficiada pela política pública de regularização fundiária do Ministério das Cidades, havendo a propositura de mais de trezentas ações de usucapião extraordinário a fim de regularizar a posse dos moradores.

Esse artigo pretende, portanto, contar a história da produção do espaço de Jardim Laranjeiras sob a ótica legal em uma dimensão micro e outra macroespacial: no primeiro enfoque debruçamos o olhar sobre o espaço concebido - na tríade Lefebvriana $^{2}$ - através do projeto aprovado de loteamento, e sua imbricação com o espaço percebido, o loteamento irregular, carente de regularização fundiária; no olhar macroespacial, buscamos compreender como essa categoria jurídica desvela uma realidade territorial, já que esse espaço é inserido como periferia tanto no município quanto na região metropolitana do Rio de Janeiro, reforçando a lógica micro e com ela dando as mãos. Por fim, essa dialeticidade entre espaço concebido e espaço percebido se reflete no Plano Diretor do município, que reconhece todos os problemas da área e planeja solucioná-los tendo como referência o direito à cidade e à moradia digna, direitos fundamentais na realização da dignidade humana.

Cabe-nos ressaltar que esses direitos fundamentais são o norte de nossas atividades, sejam práticas ou reflexivas. Desta forma, ao analisar o caso de

2 Lefebvre (2006) afirma que a produção do espaço é dividida em três dimensões ou processos dialeticamente interconectados, que são a prática espacial (aquela que percebemos pelo uso do nosso corpo, seja no trabalho, nos deslocamentos diários, nas relações familiares); as representações do espaço (o espaço planejado pelos urbanistas, arquitetos, pela ciência em geral); e os espaços de representação (aqui não há necessariamente um espaço, se trata das relações simbólicas que as pessoas constroem com os espaços), ensejando o espaço percebido, o espaço concebido e o espaço vivido respectivamente. 
Jardim Laranjeiras, nossa tentativa é buscar compreender a dimensão jurídica que envolve a garantia do direito à moradia e à cidade de seus moradores.

O objetivo do artigo, portanto, é demonstrar que sim, a lei é um dos elementos de produção e reprodução do espaço, colaborando necessariamente na prática espacial e nas representações do espaço, facilitando ou dificultando o acesso a direitos fundamentais, sendo essencial o aprofundamento do estudo e do aprimoramento do Direito Urbanístico para o desenvolvimento territorial, a melhor qualidade de vida e cidades mais saudáveis.

\section{Que espaço?}

\subsection{A metrópole fluminense e a periferia de Nova Iguaçu}

O Rio de Janeiro é uma cidade importante na história do Brasil. Teve sua ocupação ainda no século XVI por conta de sua localização estratégica: uma Baía e dois morros muito próximos que facilitavam a defesa de toda a região, dificultando a entrada de embarcações, sendo possível o controle da área. A principal atividade econômica naquele momento era a extração do pau-brasil, e sua exportação para Portugal.

Quando o pau-brasil acabou, a colônia portuguesa deixou de interessar à metrópole, e a cidade fica abandonada. Esse momento somente será superado a partir da descoberta do ouro em Minas Gerais, no final do séc. XVII, início do XVIII. O Rio volta então a ter um papel comercial importante: será pelas águas da cidade que chegarão os escravos para Minas e que sairá o ouro para Portugal.

Em 1763 o Rio de Janeiro passou a ser capital da colônia e sede do ViceReinado. Em 1808, a vinda da família real para o Brasil e a abertura dos portos às nações amigas reforçaram o desenvolvimento da cidade, principalmente se considerado o fato de que ela é, naquele momento, sede do Império português. $O$ comércio, principalmente com a Inglaterra, vai fazer a cidade consolidar-se de vez como espaço urbano.

A necessidade de moradia da Corte dividiu a cidade entre dois pontos: São Cristóvão, para onde se dirigiu D. João, e Laranjeiras e Botafogo, para onde foi D. Carlota Joaquina. Em 1810 criou-se a cidade nova, que vai fazer a ligação (urbanizada) do campo de Santana com a Quinta da Boa Vista, criando os dois vetores de desenvolvimento da cidade: a zona norte e a zona sul. Com a inauguração da Estação Central da Estrada de Ferro D. Pedro II, em 1858, a expansão para o subúrbio se consolida.

Assim, com a diversificação das atividades econômicas e o rápido crescimento da população, a cidade mudará rapidamente, apresentando melhorias sucessivas até 1870, ano que Mauricio de Abreu (MENDES, 2005) destaca como significativo para a evolução urbana da cidade. E entre 1903 e 1906, após a abolição da escravatura e a proclamação da república, foi implementada uma ampla política de renovação urbana, promovida pelos governos federal e municipal.

A urbanização significativa no Brasil, e especialmente no Rio de Janeiro, se vincula ao discurso de modernização, e a uma industrialização acelerada e tardia. A modernização do país, ou seja, sua urbanização, é vista como sinônimo de progresso, desenvolvimento. A partir daí, ocorrem imensos deslocamentos da população para as cidades, vendidas como o espaço do 
sonho, do progresso, da possibilidade de "vencer na vida". A rede urbana é constituída, então, a partir dos interesses colocados pelo processo de industrialização, que culminará na institucionalização das regiões metropolitanas no período da ditadura militar.

Já a região da Baixada Fluminense, entre o início do século XVII até meados do século XX, vai ter uma produção agrícola voltada para o consumo interno, produção que era levada para o Rio de Janeiro através de seus rios navegáveis (MAGALHÃES et al, 2013). Esse fato inicial já demonstra a submissão do território iguaçuano aos interesses fluminenses.

A ocupação da localidade se dá partir do século XVIII, mas somente no início do século $\mathrm{XX}$, com obras de drenagem realizadas em toda a região é que os migrantes, buscando melhores condições de vida na capital Rio de Janeiro, vão ocupar aquele espaço que se caracterizará como periférico dentro da Região Metropolitana.

Nesse sentido, a expansão da cidade do Rio de Janeiro através da conurbação que produz sua metropolização se deu em diversas etapas, segundo Fabiana Dias (2005), etapas que valem ser transcritas:

A urbanização da cidade do Rio de Janeiro e o crescimento de sua população estão articulados ao mercado imobiliário, à expansão industrial e ao transporte de massa, que determinaram o vetor de ocupação do eixo suburbano que extravasa em municípios vizinhos, dando origem ao processo de metropolização, ou seja, ao fenômeno de conurbação, que se acelerou nos anos de 1920, devido ao desenvolvimento da produção de energia pela Light, à modernização dos sistemas de transporte ferroviário e ao desenvolvimento da produção industrial. O período seguinte, de 1930 a 1950, pode ser descrito como a fase que marca a grande expansão física da metrópole, atingindo a oeste o município de Nova Iguaçu e, a leste, o de São Gonçalo e que se caracterizou por loteamentos a baixo custo e conjuntos habitacionais com precárias condições de infraestrutura básica. A partir da década de 1950, com a construção das grandes rodovias, como a Avenida Brasil e a Rodovia Presidente Dutra, tem-se a intensificação do processo de metropolização. Anos depois, na década de 1970, temos mais um adensamento das áreas urbanizadas do que um avanço no espaço, enquanto, na década de 1980, um novo processo de periferização toma lugar, com as populações de mais baixa renda ocupando áreas urbanas de novos bairros da área conurbada à metrópole e de municípios mais distantes, como Magé, Itaboraí e Itaguaí, enquanto nas áreas centrais o preço da terra é cada vez mais alto. $\mathrm{Na}$ década seguinte, surgem novas centralidades e intensifica-se o deslocamento da população do núcleo metropolitano para sua periferia em municípios como: Mangaratiba, Itaguaí, Paracambi, Maricá, Itaboraí e São Gonçalo. (DIAS, F. 2005, p.164)

A formação da metrópole do Rio de Janeiro se dá durante todo o século $\mathrm{XX}$, sendo certo que para a região aqui estudada os sistemas de integração ferroviário e rodoviário e a expansão dos loteamentos, como demonstra a autora, são decisivos para a ocupação desse espaço. A partir de 1950 "percebe-se um surto industrial na região" (MAGALHÃES et al, 2013, p. 28), mas, para Dias, 
(...) a urbanização das áreas periféricas não se articulou pela industrialização, mas sim pelo mercado imobiliário e pelo sistema de transporte coletivo, que tiveram papel determinante no crescimento urbano da Região Metropolitana, que se caracterizou por dois processos, resultantes da inadequação de políticas e instrumentos de planejamento e gestão urbana: a periferização da população em áreas sem infraestrutura e a formação de núcleos favelados resultantes da impossibilidade de grande parte da população, inclusive trabalhadores, ter acesso ao mercado imobiliário formal. (DIAS, F., 2005, p.165)

Essa observação de Dias tem total relevância para o caso estudado, uma vez que se trata da periferização da população por conta da dinâmica imobiliária. A questão da moradia em Nova Iguaçu no século XX pode ser juridicamente traduzida como a dificuldade de acessar a propriedade da terra urbanizada pela população pobre, o que permeia toda a história fundiária do país, e contribui para o nosso significativo déficit habitacional.

De fato, a região aqui estudada cresceu de uma maneira menos formal e regular, servindo principalmente como área para habitações dos trabalhadores que trabalhavam na cidade central, mas não podiam pagar para morar em solo valorizado. E também para a instalação de indústrias poluidoras, que não poderiam mais estragar a qualidade do ambiente no núcleo metropolitano, constituindo-se assim, em prefeito exemplo da narrativa de Fabiana Dias.

\subsection{A Formação do espaço de Jardim Laranjeiras}

Jardim Laranjeiras é uma comunidade localizada no bairro de Cabuçu, no município de Nova Iguaçu, região da Baixada Fluminense, Rio de Janeiro. Nova Iguaçu é considerado o "município mãe" da Baixada Fluminense, tanto por ser o mais antigo quanto por dele terem surgido oito dos treze municípios que compõem a região (MAGALHÃES et al, 2013, p. 40).

Como colocado, a área territorial da Baixada no período datado entre o início do século XVII até meados do século XX, se distinguia pela produção agrícola, especialmente de cana de açúcar, mandioca e laranja, dentre outros produtos de subsistência. O transporte dessas mercadorias era feito através de seus rios, à época navegáveis, para serem consumidos na cidade do Rio de Janeiro, assim como no exterior. (MAGALHÃES et al, 2013, p. 23).

A produção de laranja teve papel tão importante na economia da cidade que ela chegou a ficar conhecida como "a cidade perfume", porque as laranjeiras, em floração, perfumavam todo o percurso das ferrovias existentes. Como diversos outros pontos do município, nosso caso referência era formado por grandes áreas de laranjais.

A crise econômica mundial ocorrida no período entre guerras e especialmente durante a Segunda Guerra Mundial, quando as exportações são interrompidas, acaba por fazer a citricultura iguaçuana entrar em declínio (MAGALHÃES et al, 2013, p.41). No entanto, “já se iniciava a expansão urbana que resultou no processo de integração urbana à metrópole fluminense" (MAGALHÂES et al, 2013, p. 41). E a expansão 
de loteamentos, como já mencionado, é um dos motivos de intensificação do processo de urbanização da Baixada, desencadeada justamente pelas crises na produção agrícola que a região passou. Lotear, segundo Simões (2006), é uma opção que sobra para a elite proprietária de terras, totalmente endividada com exportadores ou bancos locais:

Assim, os que escapam da falência e não perdem suas terras conseguem vende-las para incorporadores e se transformam em comerciantes ou se transformam, eles mesmos, em loteadores, transformando as suas chácaras em loteamentos, seja por conta própria, seja em parceria com imobiliárias locais ou do Rio de Janeiro. (SIMÕES, 2006, p.120)

E Nova Iguaçu contava ainda com a benevolente ação da Prefeitura Municipal, imbuída da intenção de facilitar a ocupação das terras particulares do município, substituindo o rural pelo urbano:

No caso de Nova Iguaçu, por exemplo, as chamadas "construções do tipo proletário" contavam com grandes facilidades por parte da prefeitura, que limitava suas exigências ao pagamento de uma pequena taxa destinada à aprovação de planta impressa, e fornecida pela própria municipalidade. (ABREU, 2011, p.123)

Esse é então o cenário em que a comunidade de Jardim Laranjeiras surge, sendo reflexo e refletindo a realidade territorial em que está inserida. Maurício de Abreu (2011) traz uma tabela em que demonstra a aprovação de loteamentos em Nova Iguaçu por década, em que a década de 1950-1959 bate recordes tanto de número de loteamentos aprovados - 917 - quanto de lotes 166.816 (ABREU, 2011, p. 121).

Tendo como referência a certidão de ônus reais expedida pelo Cartório do $5^{\circ}$ Ofício de Registro de Imóveis de Nova Iguaçu, o projeto de loteamento, que se encontra registrado às folhas 583, do livro 8-N, do referido Cartório, foi feito em 1957. A gleba total registrada tinha a dimensão de $1.194 .150,00 \mathrm{~m}^{2}$, tendo os proprietários desmembrado uma área de $394.000,00 \mathrm{~m}^{2}$. Essa área foi novamente parcelada, de acordo com o Registro de Imóveis, em 686 lotes, cada um possuindo $360,00 \mathrm{~m}^{2}$.

Vale lembrar que, nessa época, era o Decreto-Lei ${ }^{0} 58$, de 10/12/1937 que regulamentava o "loteamento e a venda de terrenos para pagamentos em prestações.” Esse Decreto-Lei estabelecia o procedimento para parcelamento do solo urbano ou rural de uma forma muito menos trabalhosa do que a atual Lei 6766/79. Além de não contar, necessariamente, com a aprovação prévia na prefeitura, constituindo todo o processo de regularização apenas no cartório de registro de imóveis, não obrigava o início das obras de infraestrutura antes das vendas dos lotes e, tampouco criminalizava a conduta do loteador que não cumprisse suas obrigações.

Assim, a situação inicial de Jardim Laranjeiras, em termos estritamente fundiários, é de regularidade, ou seja, o loteamento foi devidamente registrado, o que pressupõe o depósito no Registro de Imóveis de um memorial com a identificação e descrição do imóvel, cronologia de seus proprietários, projeto de loteamento, planta do imóvel, exemplar do contrato de compromisso de compra e venda e certidão negativa de ônus reais. Depositados esses 
documentos, o oficial do registro tornava público o depósito através de edital publicado três vezes. Se não houvesse impugnação de terceiros procedia-se ao registro.

Embora houvesse a regularidade fundiária, a urbanística não ocorreu em Jardim Laranjeiras, gerando, portanto, a irregularidade do loteamento. Veríssimo (2007), em artigo que analisa a situação fundiária do município do Rio na mesma época, faz remissão a um Decreto-Lei municipal que exigia

(...) a obrigatoriedade de obtenção de prévia licença da Prefeitura para a execução de arruamento ou abertura de logradouro, em qualquer das zonas do Distrito Federal.

(...)

Segundo, ainda, o Decreto-Lei 6000, o “interessado” na execução do parcelamento deveria assumir o compromisso de só efetuar a venda dos lotes e a construção de prédios nos mesmos após o reconhecimento dos logradouros pela Prefeitura, o que implicava - além da aprovação do projeto de parcelamento - a obtenção da aceitação, pelo órgão competente da Prefeitura, de todas as obras de urbanização (...) (VERÍSSIMO, A.A., 2007, p.151)

Esse Decreto-Lei era municipal e, portanto, só incidia no território do antigo Distrito Federal do Rio de Janeiro, tendo sido tacitamente revogado pelo Decreto-Lei 68/37, que era federal. No município aqui analisado, apenas esse último vigorava. Essa era uma contradição normativa que se complementava, e que reflete o processo de hierarquização espacial da região metropolitana do Rio de Janeiro, como coloca Abreu ao explicar os fatores que geraram a explosão demográfica da Baixada Fluminense à época:

(...) o baixo preço dos lotes (posto que nada incorporavam de benfeitorias), e a possibilidade de aí se construir uma moradia com o mínimo (ou, em muitos casos, a total ausência) de exigências burocráticas, em contraposição ao progressivo controle da construção exercido pelo Estado no Distrito Federal (Abreu, M., 2011, p. 121).

É importante ressaltar como as leis urbanísticas favoreceram o processo de periferização, uma vez que o rigor nas exigências para lotear se concentraram na legislação da cidade do Rio de Janeiro, então Distrito Federal, ao passo que em Nova Iguaçu não só não haviam muitas exigências como a inobservância delas era "perdoada", como demonstra Maurício de Abreu (2011).

Então, naquele momento, desde que fora da cidade central, era possível que houvesse um loteamento regular do ponto de vista fundiário, porém irregular do ponto de vista urbanístico, o que juridicamente se denominou de loteamento irregular e que é justamente o caso de Jardim Laranjeiras.

Sob outro aspecto, não custa lembrar que as leis de loteamentos se aplicavam aos espaços urbanos, o que vai forçar, ao menos no âmbito normativo, uma urbanização de zonas rurais, como foi o caso da área em que Jardim Laranjeiras se situa. A questão é que a combinação desses dois aspectos gera um espaço periférico de urbanização precária, um problema fundiário, urbanístico e ambiental que se prorroga no tempo e no espaço. 


\section{Questões territoriais}

\subsection{A questão metropolitana}

As desigualdades socioespaciais aqui colocadas são características das grandes cidades contemporâneas. Como o acesso à terra é mediado pela possiblidade de pagar, ou seja, o acesso à propriedade privada do solo se dá mediante compra e venda, as possibilidades de morar, trabalhar, vivenciar espaços de lazer são diferentes para cada classe social. Assim, a produção (legal) do espaço urbano no capitalismo tem como consequência natural a segregação socioespacial.

Essa segregação gerou, ao longo do tempo, a expansão das cidades pelo tecido urbano, ou seja, a metropolização desses espaços. A metrópole é a forma comum do tecido urbano já no século XX. A expansão das grandes cidades para além do tecido inicial, formando inicialmente uma conurbação (com cidades periféricas no entorno da principal) e uma rede urbana, somado ao aumento da população em toda essa área, é o que vai gerar a metrópole.

A formação da rede urbana advém das relações que as cidades vão desenvolvendo ao longo do espaço e do tempo, realizando trocas que vão estabelecer dependência e fluxos intermitentes de pessoas e bens. Tais relações acabam por transformar o espaço, que acaba por ser "costurado", dando a ideia de continuidade e de homogeneidade da paisagem. A rede urbana cria uma teia onde existem desde

pequenos centros quase sem centralidade, que somente influenciam o território do município (ou seja lá o nome que, dependendo do país, tiver a unidade político-administrativa local) onde se encontram e para o qual servem de sede, até grandes metrópoles, ao longo da rede urbana se distribuem núcleos urbanos com tamanhos e centralidades muito variadas. (SOUZA, M.L. 2011, p.51)

Ainda segundo Marcelo Lopes de Souza (2011), a metrópole se difere da aglomeração urbana porque nela há um município polo, um núcleo metropolitano, ao passo que as aglomerações são formadas por cidades pequenas ou médias. Desta maneira, a ideia de metrópole em nossa época tem ainda como referência o predomínio de uma cidade sobre outras, em uma relação desigual, em que a região metropolitana se confunde com a metrópole, ou seja, a reunião de diversos municípios distintos é compreendida como um único território.

Portanto, a metrópole é apresentada como a cidade principal dentro de um conjunto de cidades contínuas no tecido urbano, que estabelecem entre si uma relação de dependência, especialmente no que se refere às questões de oferta de emprego, mão-de-obra e moradia. A continuidade do tecido urbano, associada à distribuição desigual no território metropolitano desses três elementos, geram uma circulação diária e intermitente de pessoas, riquezas e energias. Contudo, nem a ocupação nem a circulação se fazem de maneira equânime, tampouco a relação que a cidade central estabelece com as outras - periféricas. A hierarquia entre esses espaços é uma das principais características definidoras da relação entre eles.

Ao observarmos a relação entre a cidade do Rio de Janeiro com os outros municípios que compõem a região metropolitana, essa hierarquização pode 
ser vista sob a esfera produtiva, social, ambiental, cultural ou econômica. O Rio de Janeiro define usos e funções para territórios de sua área de influência, como alocação de aterros sanitários, presídios, etc. No século XX era possível observar Nova Iguaçu e outras periferias como cidades dormitórios, onde há concentração de indústria poluente e da classe trabalhadora. No caso de Jardim Laranjeiras, como dito, havia a produção de laranja para exportação e depois, com o processo de urbanização, um loteamento cuja irregularidade foi incentivada a fim de garantir moradia para os pobres e uma forma de lucro para os ex- donos dos laranjais.

Essa realidade espacial demorou para ser objeto de atenção dos juristas. Em termos normativos, Paula Ravanelli Losada (2010) observa que a gestão metropolitana se inicia no regime militar, especialmente na década de 1970. Segundo o texto do art.164 da Constituição de 1967, a competência para estabelecer regiões metropolitanas era da União e o critério de formação era o pertencimento dos municípios à mesma comunidade socioeconômica, como ele dispunha.

Na Constituição de 1967 - e também na "emenda de 1969" - a natureza conferida às regiões metropolitanas era meramente a de região de serviços comuns, atribuindo-se a titularidade do interesse metropolitano a uma forma compulsória de associação de municípios. Vale registrar que não havia no texto constitucional qualquer menção à competência dos estados-membros em matérias metropolitanas; contudo, no momento em que as primeiras regiões metropolitanas foram criadas pela lei complementar 14, de 1973, já no período de crescente centralização financeira e autoritarismo político, a titularidade dos interesses metropolitanos foi conferida aos estados-membros, excluindo os municípios e a sociedade do processo decisório (Gouvêa, 2005) (LOSADA, 2010, p. 263)

A autora defende que a gestão metropolitana na época da ditadura militar foi bem sucedida, tendo alguns casos de "avanços consideráveis, sobretudo do ponto de vista urbanístico e ambiental" (LOSADA, 2010, p.265). Explica ainda que o modelo de gestão ficou a cargo de cada estado, que podia escolher a forma jurídica que melhor lhe atendesse e que a participação dos municípios seria estimulada - mas não obrigatória.

No caso específico do Rio de Janeiro, a situação sui generis de ser, ao mesmo tempo, Estado e capital da República, como ressaltam Correia e Farias (2014), dentre outros, impediram durante um tempo a possibilidade de criação da Região Metropolitana. Além disso, essa divisão acabou fortalecendo o modelo dual de ocupação desse espaço, como narra Maurício de Abreu (2011):

A antiga situação, em que o núcleo se via separado de suas periferias e do seu território com a divisão da Região Metropolitana em dois estados, contribuiu ainda para reforçar sobremaneira a dicotomia núcleo/periferia. A cidade do Rio de Janeiro, e mais especificamente o seu núcleo, concentrou todos os recursos, muitas vezes aplicando em obras suntuosas e de prestígio, sem reinvestir nada numa região onde não tinha responsabilidades políticas. O resultado foi um núcleo forte, cercado por uma periferia pobre e superpovoada, onde eram deixados todos os ônus para o antigo Estado do Rio, enquanto a Guanabara auferia todas as vantagens disponíveis. (ABREU, 2011, p. 17) 
Essa situação somente foi superada, em termos jurídicos, com a fusão dos Estados do Rio e da Guanabara, o que também interessava ao governo militar para tornar o Rio um polo de desenvolvimento, buscando alcançar São Paulo. Assim, através da Lei Complementar $n^{\circ} 20 / 74$, a mesma que prevê a fusão dos dois estados, é criada a Região Metropolitana do Rio de Janeiro (RMRJ), submetida ao governo estadual, e constituída pelos seguintes municípios: Rio de Janeiro, Niterói, Duque de Caxias, Itaboraí, Itaguaí, Magé, Maricá, Nilópolis, Nova Iguaçu, Paracambi, Petrópolis, São Gonçalo, São João de Meriti e Mangaratiba ${ }^{3}$.

A ideia era gerir interesses comuns de forma integrada, buscando certa coesão territorial. Assuntos como saneamento, transporte, serviços de saúde são demandados em toda a rede urbana que compõe o tecido metropolitano e, portanto, sua gestão deve ser pensada dessa forma.

Contudo, A Constituição Federal de 1988 previu como entes federados a União, os Estados, os Municípios e o Distrito Federal, ou seja, são esses espaços territoriais que detêm autonomia política. As regiões metropolitanas são, assim, meras descentralizações administrativas dos Estados, conforme estabelece o art.25, $\$ 3^{\circ}$, que coloca a competência desses para "instituir regiões metropolitanas, aglomerações urbanas e microrregiões, constituídas por agrupamentos de Municípios limítrofes, para integrar a organização, o planejamento e a execução de funções públicas de interesse comum." Portanto, a região metropolitana é espacialmente maior que um município, é, na verdade, uma superposição de diversos municípios, mas não é ente federativo, não tendo autonomia política, não tendo competências próprias e sendo estabelecida, organizada e planejada pelo estado.

Esse foi um sério entrave na tentativa de gestão metropolitana pós 88 , sendo objeto de duas $\mathrm{ADIs}^{4}$, todas duas vencidas, tendo a interpretação do STF sido no sentido de que "A Região Metropolitana é uma autarquia territorial, intergovernamental e plurifuncional, sem personalidade política; a criação de um ente regional não significa a transferência de competências municipais, constitucionalmente estabelecidas, para o Estado.” (ADI 1842)

Assim, em 2014, é criada a Câmara Metropolitana do Rio de Janeiro, que tem

[...] a missão de coordenar ações de interesse comum aos 21 municípios da Região Metropolitana do Rio de Janeiro (RMRJ) relacionadas à mobilidade, preservação do patrimônio natural e histórico, meio ambiente, saneamento e abastecimento de água, ordenamento espacial, entre outros temas.

O novo órgão recebeu as atribuições de propor um novo arcabouço legal, consagrando um modelo de governança para a RMRJ, e de intermediar a cooperação entre os vários níveis de governo.

A Câmara conta com o Grupo Executivo de Gestão Metropolitana, que teve como prioridades estabelecidas a produção de uma nova base cartográfica dos 21 municípios da região; a criação de um Sistema de

3 Atualmente compõem a RMRJ os seguintes municípios: Belfort Roxo, Duque de Caxias, Guapimirim, Itaboraí, Itaguaí, Japeri, Magé, Maricá, Mesquita, Nilópolis, Niterói, Nova Iguaçu, Paracambi, Queimados, Seropédica, São Gonçalo, São João de Meriti, Tanguá, Cachoeiras de Macacu e Rio Bonito.

4 Ações Direta de Inconstitucionalidade (ADI) números 1841-RJ e 1842-RJ. 
Informações Geográficas para a RMRJ; e a coordenação da construção do Plano Estratégico de Desenvolvimento Urbano Integrado (PDUI), também conhecido como Modelar a Metrópole. (Disponível em: < http:// www.modelarametropole.com.br/rmrj/>)

A estrutura pensada para a Câmara e suas atuações iniciais estão todas seguindo o Estatuto da Metrópole, Lei federal $n^{0} 13.089$, criada em de 12 de janeiro de 2015. Logo, o país tem agora uma base normativa para fundamentar a administração metropolitana, reconhecendo, ao menos no plano legal, as desigualdades territoriais existentes entre os municípios, haja vista que o Estatuto trabalha com princípios que visam maior equidade, tais como: a) prevalência do interesse comum sobre o local; b) compartilhamento de responsabilidades para a promoção do desenvolvimento urbano integrado; c) autonomia dos entes da Federação (art. $6^{\circ}$, incisos I, II e III do Estatuto da Metrópole). Basta saber se a prática da Câmara Metropolitana do Rio de Janeiro transformará as relações socioespaciais até aqui construídas.

\subsection{A questão fundiária}

O loteamento irregular "é parcelamento aprovado, mas não registrado ou, ainda que registrado, com falha na implantação." (AMADEI, V.C.; AMADEI, V.A , 2012, p.14). Assim, Jardim Laranjeiras nasce e cresce sem asfalto, luz elétrica e água encanada. Inserido no bairro de Cabuçu, não havia transporte público para chegar ao centro de Nova Iguaçu, sendo o deslocamento feito por caminhões, ou kombis. Tampouco havia escola ou posto de saúde. Nesse sentido, é possível vislumbrar como o Decreto-Lei 58/37, ao não exigir que as obras obrigatórias fossem efetivamente realizadas para somente depois serem os lotes vendidos, acabou por produzir espaços sem infraestrutura nenhuma, embora com regularidade na propriedade fundiária. Além disso, a permissividade da Prefeitura, em uma tentativa de urbanizar a região, gerou apenas uma área não rural, mas sem equipamentos públicos básicos, criando uma área urbana precária, típica das moradias populares do país.

O local hoje, embora ainda não completamente urbanizado, se insere mais no tecido urbano e na malha viária, contando com duas escolas públicas próximas, vasto comércio e condução. De acordo com o presidente da Associação de Moradores do bairro de Jardim Laranjeiras, José Avelino da Costa, tudo o que conseguiram no loteamento foi pelo próprio esforço conjunto da comunidade, sendo que tais conquistas são razoavelmente recentes.

Além da questão urbanística, a regularização da propriedade da terra acabou se colocando como demanda também. O último ato formal - o registro do contrato de compromisso de venda - data de 1961, e desde então os lotes foram sendo ocupados ou transferidos informalmente, garantindo o direito à moradia através da posse. Desta forma, na tríade dialética lefebvriana, o espaço percebido se coloca como predominante na situação de Jardim Laranjeiras, uma vez que a irregularidade da terra se configura como prática espacial.

Em 2010 ocorre a tentativa de regularizar o loteamento, a partir de um convênio celebrado entre o Ministério das Cidades, a Prefeitura Municipal de Nova Iguaçu e a Fundação Bento Rubião, entidade civil sem fins lucrativos sediada no Rio de Janeiro, que ficou a cargo de pensar ações de regularização fundiária. 
Assim, pelo tempo transcorrido e pelos instrumentos existentes no nosso ordenamento jurídico, a melhor opção foi a propositura de ações de usucapião. A Fundação organizou essas ações em conjunto com a Associação de Moradores do Bairro Jardim Laranjeiras, presidida pelo senhor José Avelino.

As ações foram propostas em 2010 na modalidade de usucapião extraordinário, fundamentada no artigo 1.238 do Código Civil, porque os lotes, além de totalmente individualizados, tinham dimensão maior do que duzentos e cinquenta metros quadrados $\left(250 \mathrm{~m}^{2}\right)$, o que impossibilitou, portanto, a propositura de usucapião especial urbano.

Em 2016, a Fundação Bento Rubião transferiu as ações para o Núcleo de Assessoria Jurídica Popular (NAJUP) Marli Coragem, da Universidade Federal Rural do Rio de Janeiro.

Observando os processos em curso, é possível tecer algumas considerações procedimentais acerca dessa modalidade processual de regularização fundiária.

Apesar de em alguns processos haver a anexação da certidão de ônus reais constando o registro do compromisso de compra e venda, quem figura no polo passivo da ação são os proprietários do loteamento, e não os compromissários compradores, e, apesar do transcurso do tempo, estes ainda não foram citados.

A não citação dos réus parece-nos algo completamente normal, dada a complexidade das ações de usucapião. Embora o objetivo da mesma seja concretizar o direito de propriedade àqueles que detêm posse com animus domini, e, portanto, garantir o direito à moradia, a prática judiciária limitava - e muito - o reconhecimento do direito. Isto porque as exigências estatuídas no antigo Código de Processo Civil para a ação de usucapião eram extremamente complexas na prática.

O novo Código de Processo Civil parece ter simplificado tais exigências, embora só a prática judiciária poderá nos dizer se de fato houve essa simplificação. Além de não ter estabelecido explicitamente o procedimento de usucapião como especial, o novo Código apenas tratou do assunto em artigos esparsos, além de ter aprofundado o procedimento da usucapião extrajudicial, inaugurado em nosso ordenamento pela Lei 11977/09.

Pelas novas regras, podemos afirmar que:

(1) Não será mais necessária a juntada de planta do imóvel, o que é muito útil, pois há sempre dificuldade de contratar um arquiteto no caso de regularização para hipossuficientes;

(2) A intervenção do MP em todos os atos do processo não será mais obrigatória, uma vez que não faria mais sentido, após a Constituição de 1988, manter o Parquet como fiscal de direitos individuais, o que já era, enfim, uma reclamação constante de seus membros;

(3) A intimação das Fazendas Públicas também não aparece como requisito no novo CPC. A intervenção das Fazendas na ação de usucapião refere-se à possibilidade de ser a terra usucapida pública ou conter restrição de natureza administrativa. Parece que a citação por edital prevista no art. 259, I é uma forma de dar 
publicidade à ação e oportunidade de manifestação às Fazendas sem a necessidade de intimar cada uma delas e aguardar, sem prazo legal, que se manifestem;

(4) Os "réus em lugar incerto" e os "eventuais interessados" também desapareceram no novo CPC. Os réus certos em lugares incertos devem ser buscados através de editais e é possível que se mantenha a prática de nomeação da Curadoria de Ausentes. Mas citar "eventuais interessados", nestes termos, sempre nos pareceu uma exigência desnecessária, como se não fossem suficientes todas as certidões exigidas, o registro do imóvel e a comprovação da posse para demonstrar a situação de direito do usucapiente;

(5) Em contrapartida, os confinantes devem ser citados pessoalmente (art.246, $\$ 3^{\circ}$ ), o que já vem ocorrendo nas ações de usucapião de Jardim Laranjeiras, contudo, as certidões que chegaram aos dois cartórios em que houve expedição de mandado foram negativas, o que parece demonstrar que o problema permanece quando se trata de área pobre, com pouca individualização urbanística, como é o caso do loteamento.

Outros requisitos se mantêm por constarem no Código Civil, tais como a necessidade de provar que os autores não são proprietários de outro imóvel ou não sofreram oposição em sua posse - o que se faz mediante certidões expedidas por cartórios extrajudiciais. E embora seja majoritária a posição jurisprudencial acerca de que a concessão de justiça gratuita abarca todos os atos necessários para o desenvolvimento regular do processo, em alguns casos dentre as ações em Nova Iguaçu foi necessário interpor Agravo de Instrumento para garantir a expedição gratuita de tais documentos.

Em sendo assim, podemos perceber que a ação de usucapião é um instrumento importante no acesso ao direito à moradia, embora não o único, mas que na prática torna-se um caminho árduo para quem pretende se valer dela para regularização fundiária. Esperamos, no entanto, que as mudanças introduzidas pelo novo CPC facilitem o trâmite das novas ações de usucapião que pretendemos propor para dezessete moradores da comunidade Jardim Laranjeiras.

De toda forma, as questões aqui levantadas demonstram como a legislação pode não apenas produzir irregularidade, mas também como pode dificultar a regularização fundiária, ao menos na esfera judicial. Nesse sentido, parecenos que o direito à propriedade permanece como absoluto nas mentes dos operadores jurídicos e é por isso que os mais comprometidos têm questionado se vale a pena insistir nela, afinal, importante é garantir o direito à moradia digna para todos, independente da forma jurídica que esse direito se revista.

\section{0 Plano Diretor de Nova Iguaçu: quando o espaço concebido retrata o espaço vivido}

O Plano Diretor de Nova Iguaçu (PDNI) é a Lei 4.092/11. Elaborado durante uma gestão municipal mais à esquerda, foi construído de forma participativa, buscando organizar e classificar o território municipal a partir de suas realidades 
e potencialidades. Esse modo de elaboração gerou uma norma jurídica que traduz, em seus artigos e mapas, a realidade espacial de Jardim Laranjeiras, enquanto planeja a melhoria desse espaço. Nesse sentido, é uma norma em que é possível se visualizar tanto o espaço percebido quanto o concebido.

Um ponto interessante da norma municipal é que define não só o direito à cidade como princípio, mas também seu conteúdo, entendido como "o direito à terra urbana, à moradia, ao saneamento básico, à infraestrutura, ao transporte, à mobilidade das pessoas com deficiência, aos serviços públicos, ao trabalho, ao lazer e à cultura;" (Art.5 $5^{\circ}$ III, PDNI). E o que é moradia digna, demonstrando o reconhecimento da problemática no município como também a intenção de concretizar esses direitos, superando os tipos abertos da legislação, que deixam à critério da Administração Pública seu preenchimento de acordo com a conveniência e oportunidade:

\section{Por moradia digna entende-se aquela que: \\ I. tem acesso à rede de infraestrutura e aos serviços de transporte coletivo, abastecimento de água, esgoto, iluminação, coleta de lixo, telefonia, pavimentação e aos equipamentos sociais; \\ II. dispõe de instalações sanitárias adequadas; \\ III. possui condições mínimas de conforto e habitabilidade; \\ IV. é passível de regularização fundiária. (Art.17, $\$ 1^{\circ}, \mathrm{PDNI}$.)}

A área de Jardim Laranjeiras está inserida no bairro de Cabuçu, não se constituindo formalmente como bairro, embora a população assim se refira ao lugar. Dentro do Macrozoneamento definido no PDNI, a área inteira é classificada como Macro-Zona de Urbanização Precária, refletindo, assim, a realidade espacial do lugar, o que nem sempre é comum nos Planos Diretores.

Em termos de planejamento, é possível apontar que o município de Nova Iguaçu pretende priorizar nessas áreas, "a implantação ou complementação de infraestrutura e equipamentos sociais, segundo as necessidades da população, provendo acessibilidade, desenvolvendo polos de emprego, estimulando a instalação de comércio e serviços" (Art.62, PDNI ), estabelecendo ainda que "será a área prioritária na elaboração e execução de Projetos e Programas de implantação de infraestrutura, regularização fundiária e saneamento básico." (Art. 63, parágrafo único, PDNI.)

Além da questão da infraestrutura, a regularização fundiária também é meta da lei, aparecendo algumas vezes a expressão "loteamentos irregulares e clandestinos de baixa renda" como objeto dessa política. Há também a definição dessas áreas como Zonas Especiais de Interesse Social. Logo, é possível perceber que a questão fundiária em sua dimensão legal e de infraestrutura foi priorizada, a fim de concretizar o direito à cidade e à moradia digna.

A palavra Cabuçu aparece oito vezes no PDNI, em quatros delas relacionadas à questão de criação de centralidades (locais), numa tentativa clara de reterritorializar a (até aqui) periferia. Está prevista a implantação de uma série de equipamentos urbanos, que vão desde infraestrutura, como iluminação, pavimentação, abrigo de ônibus; serviços públicos essenciais, como escolas de primeiro e segundo grau, biblioteca e quadra esportiva; e ainda, serviços privados, como bancos, cinemas e teatros. 
Se, por um lado, a norma reconhece a realidade de Jardim Laranjeiras, por outro, não deixa de ser lamentável tal realidade, tendo em vista a quantidade de necessidades urbanísticas desse território. De toda forma, é louvável que o espaço seja concebido a partir do espaço percebido, e é possível apontar algumas políticas implementadas na área, tais como o próprio projeto de regularização fundiária da comunidade aqui estudada; a construção de quatro conjuntos do Minha Casa Minha Vida na região, perfazendo mais de quatro mil unidades; uma das escolas estaduais já existentes passou a oferecer o ensino médio; algumas ruas tiveram obras de drenagem e pavimentação; a instalação de dois supermercados e de uma quadra esportiva. Desta forma, parece-nos haver uma tentativa de uma melhor condição espacial em Cabuçu.

\section{Conclusões}

As relações sociais se caracterizam por condicionantes econômicos, culturais, legais, espaciais. O espaço concebido é também o vivido, e a percepção de como ele se produz é fundamental para a compreensão de uma série de dinâmicas que nele se materializam.

Ao nos debruçarmos sobre o loteamento Jardim Laranjeiras podemos perceber, apenas no olhar, a precariedade de serviços e de infraestrutura. Essa realidade socioespacial pode ser explicada a partir de um estudo sobre as normas jurídicas que incidiram naquele território, sendo possível enquadrar Jardim Laranjeiras naquilo que a literatura jurídica denomina de loteamento irregular. Essa categoria expressa não apenas uma condição jurídica como também uma realidade espacial, demonstrando como a lei também é responsável por tal configuração.

A modificação dessa configuração gera demanda por um processo de regularização fundiária, que, no caso aqui comentado, se iniciou através de um edital do Poder Público e está tendo continuidade através do NAJUP Marli Coragem da UFRRJ. Os lentos avanços no decorrer do processo nos leva a considerar a dificuldade real de acesso à propriedade do solo por parte dos mais pobres. Contudo, é preciso não esquecer que o direito de propriedade não se confunde com o direito à moradia, e é esse que buscamos concretizar em nossas práticas.

Numa dimensão macro, é possível observar o mesmo espaço - Jardim Laranjeiras - como inserido em um município que se constituiu como periférico, ou seja, um município cujas funções são definidas pelo município central da região metropolitana. Desta forma, a ideia de irregularidade e de precariedade é reforçada não apenas pela legislação vigente à época, mas também pela própria hierarquização espacial existente, hierarquização esta que somente agora, já nos anos 2010, a norma jurídica pretende modificar com o advento do Estatuto da Metrópole e da criação da Câmara Metropolitana.

Podemos concluir, enfim, que a lei atua formando e conformando um espaço, tanto no plano físico - como a falta de infraestrutura urbana típica dos loteamentos irregulares - quanto no simbólico - estabelecendo a ilegalidade na ocupação da terra, e, portanto, na vida de seus moradores. A ausência de lei também constrói simbolismos e práticas sociais, como foi a hierarquização estabelecida entre a cidade do Rio de Janeiro e as cidades de seu entorno - periferias.

Já a realidade produzida pela lei gera debates, críticas, sugestões. E assim, novas elaborações normativas surgem a fim de resolver os problemas anteriores. 
Então, vemos surgir recentemente no campo do Direito Urbanístico, as novas modalidades de usucapião, a Política Nacional de Mobilidade Urbana, o Estatuto da Metrópole, a retirada de exigências desnecessárias no processo de usucapião, a nova lei de regularização fundiária, dentre outras leis e projetos de lei. Algumas consideramos avanço, outras retrocesso. Mas, independentemente de esgotar o assunto, o presente artigo visou colaborar com a ideia de que o espaço é também produzido pelas normas urbanísticas, trazendo um caso concreto para demonstrar essa afirmação. 


\section{Referências bibliográficas}

1. ABREU, M. A. Evolução Urbana do Rio de Janeiro. 4 ed. $3^{\text {a }}$ reimp. Rio de Janeiro: Instituto Pereira Passos (IPP), 2011.

2. AMADEI, V.C.; AMADEI, V.A. Como lotear uma gleba: o parcelamento do solo urbano em todos os seus aspectos (loteamento e desmembramento). 3 ed. rev. e ampl. Campinas, SP: Millennium Editora, 2012.

3. CORREIA, A.F.; FARIAS, T. Regionalismo como uma Nova perspectiva para o Federalismo Brasileiro: o Leading Case Relativo à Região Metropolitana do Rio de Janeiro. Revista Magister de Direito Ambiental e Urbanístico, v. 51, p. 5-40, 2014.

4. DIAS, F. A Questão Metropolitana. Cadernos Metrópole, V.14. - 2005. p. 149-174.

5. GUIMARÃES, I.B.B.; PEREIRA, T. C. G. . O morro e o porto: significados e interseções na região central do Rio de Janeiro. In: CAVALLAZZI, R.L.; AYRES, M.J.. (Org.). Construções Normativas e Códigos da Cidade na Zona Portuária. 1ed.Rio de Janeiro: PROURB, 2012, v. 2, p. 147-178.

6. LEFEBVRE, H. A produção do espaço. Trad. Doralice Barros Pereira e Sérgio Martins (do original: La production de l'espace. 4 éd. Paris: Éditions Anthropos, 2000). Primeira versão: início - fev.2006.

7. LOSADA, P.R. O Comitê de Articulação Federativa e o Desafio da Governança Metropolitana no Brasil. In: Klink, J. (org.). Governança das metrópoles: Conceitos, experiências e perspectivas, 259-287. São Paulo: Annablume, 2010.

8. MAGAlhãeS, A. L. et al. Alma(naque) da Baixada! Rio de Janeiro: APPH-CLIO, 2013.

9. MENDES, I. Tópicos Urbanos. [Filme- vídeo]. Produção e direção de Ivana Mendes. Depoimentos: Maurício de A. ABREU, Milton TEIXEIRA, Rachel COUTINHO, GUTA, Marília BARBOSA, Susane WORCMAN e Haroldo COSTA. Rio de Janeiro: Tríplice Produções, 2005. 1 Vídeo (DVD), 52 min. Colorido/pb. son.

10. PEREIRA, T. C. G. A Igualdade na Federação Brasileira e Seus Efeitos Desiguais na Reprodução do Espaço Metropolitano do Rio de Janeiro: o Caso da Destinação Final dos Resíduos Sólidos do Município do Rio de Janeiro na Periferia de Seropédica. 2015. 203 ps. Tese (Doutorado em Sociologia e Direito). Universidade Federal Fluminense, Niterói.

11. ROBIRA, R. T. Áreas Metropolitanas: espaços colonizados. Em: CARLOS, A. F. A. e CARRERAS, C. (orgs). Urbanização e Mundialização: estudos sobre a metrópole. 2.ed. $1^{\mathrm{a}}$ reimpressão. São Paulo: Contexto, 2012. pp.9-20.

12. SIMÕES, M. R. A Cidade Estilhaçada: Reestruturação Econômica e Emancipações Municipais na Baixada Fluminense. 2006. 313 ps. Tese (Doutorado em Geografia). Universidade Federal Fluminense, Niterói.

13. SOUZA, M.A. Recompondo a história da região metropolitana: processo, teoria e ação. Em: Metrópole: governo, sociedade e território. SILVA et all (orgs.). Rio de Janeiro: DP\&A: Faperj, 2006. Ps. 27-40. 
14. SOUZA, M. L. ABC do Desenvolvimento Urbano. $6^{\text {a }}$ Ed. Rio de Janeiro: Bertrand Brasil, 2011.

15. VERISSIMO, A. A. Parcelamento Informal do solo na Cidade do Rio de Janeiro: Raízes Legais da Informalidade. Em: COUTINHO, R.; BONIZZATO, L. (orgs.). Direito da Cidade: novas concepções sobre as relações jurídicas no espaço social urbano. Rio de Janeiro: Lumen Juris, 2007. 